\section{Response to: 'Early identification of rheumatoid arthritis; the risk of overtreatment in perspective' by Landewé}

I thank Dr van der Helm-van Mil for critically responding to my Viewpoint ${ }^{1}$ and for agreeing with most of the ideas I have brought up. ${ }^{2}$

The greater part of her argument pertains to the concepts of clinically suspect arthralgia (CSA) and undifferentiated arthritis (UA). She claims that CSA is a research field rather than clinical practice, a view I agree with. I applaud every piece of science that may give us better insight into the pathophysiology of RA. Then she warns that we must await 5 years of outstanding clinical trials before judging clinical relevance, a presumption that I find more problematic, since it implies that 'her field' anticipates on a potential future clinical benefit (this is called a 'frame'). This means there is 5 years more time to further 'frame' the concept of CSA as a condition that may be treated pre-emptively, and that any statistically significant benefit after 5 years will be explained as argument pro. It is here that I am a little bit more hesitant than Dr van der Helm-van Mil, who seems to say: 'The science will speak for itself.'

As said, the concept of CSA confuses risk of disease with presence of disease. In the Viewpoint I took CSA as a risk of rheumatoid arthritis (RA) as one example, but other examples with potential clinical relevance exist and include among others HLA-B27 carriership in first-degree relatives of HLA-B27-positive patients as a risk to develop axial spondyloarthritis ${ }^{3}$ and capillaroscopic abnormalities in patients with Raynaud's as a risk to develop systemic sclerosis. ${ }^{4}$ What these risk scenarios have in common is some form of screening.

Dr van der Helm-van Mil brings up that we do the same with treating hypertension and cervical intraepithelial neoplasia, which are both risk factors for more feared diseases, and that the public has accepted this gladly. My Viewpoint has been built on the (admittedly) bold view that risk interpretation by-and risk communication with-the public and with medical doctors is tricky business. Tricky because it usually focuses on the prediction of the 'bad outcome' and leaves the discussion about those that have to deal with waiting for a diagnosis that will never come untouched. Tricky also, since Dr van der Helm-van Mil over-rates the contribution of scientific research to all-day clinical practice. Scientific research deals with mean estimates and acceptable confidence margins in groups of individuals; clinical practice means individual patients who are anxious, may put pressure on caregivers to act rather than wait and only accept 'the best there is' as good enough. My Viewpoint reads a doctor is prone to act rather than to wait a while, in order to serve the patients' needs better. The customer is always right principle.

In the era of internet and social media, frames have more impact than 'boring' research figures. Positive frames (such as: 'RA can be prevented by pre-emptive treatment') do far better in the public opinion than negative frames (such as: 'a significant proportion of CSA patients is overtreated by costly drugs').

Admittedly, Dr van der Helm-van Mil finds herself in pretty good company: European League Against Rheumatism has launched its own campaign 'Don't delay connect today' to ask attention for diagnosing rheumatic diseases earlier. ${ }^{5}$ It is a positively framed campaign that has been warmly welcomed by patient organisations and the public. Still, this campaign does not only yield benefits; it may facilitate overdiagnosis and overtreatment too.
Dr van der Helm-van Mil argues there is more risk of overtreatment in patients with UA than with CSA. I think there is risk of overtreatment in both conditions, but the fundamental difference between CSA and UA is that a patient with UA presents with arthritis, a key finding in inflammatory rheumatology and firmly embedded as a conditio sine qua non in our classification criteria that in turn have been the basis for all our current treatments. A patient with CSA has features that may or may not precede arthritis with a certain likelihood. Patients with UA have an inflammatory disease, perhaps a self-limiting one or a different one than RA, but still a disease that warrants a treatment. In contrast, a patient with CSA only carries a risk on an inflammatory disease, but has also a very reasonable likelihood that this disease will never come.

I think the concept with which Dr van der Helm-van Mil and colleagues work is that the sequence CSA->UA-> RAactually reflects a spectrum that evolves when time passes by, with decreasing likelihoods at every transition. With the knowledge of hindsight, previous phases of CSA and UA in a patient who has clear RA today may rightfully be credited to RA in that patient. The argument that such a patient could have benefitted from pre-emptive treatment if she were treated early enough is valid in itself but also untestable. The dilemma is that you do not know upfront which of the patients with CSA will ultimately develop RA and looking back ignores those with CSA who have stayed healthy. Epidemiologists call this reverse causation. My focus in the Viewpoint was on all those others who have been confronted with the risk to develop a future disease, based on the presence of some risk factor(s), but never actually did develop this disease. It is the dark downside of screening medicine that is often swept under the carpet by screening advocates but that may have psychological, medical and economic consequences for public health. I am not so sure about public acceptance anymore once the impact of these consequences will become as clear to the public as 'the horrors of a feared disease' (this is a negative frame).

I understand Dr van der Helm-van Mil's objections very well, and I do not know how to solve the dilemma. The public, the scientific community and research funds scream for more innovative research, better tests and earlier diagnosis of chronic diseases. Grant applications require pages of text to emphasise the immediate clinical usefulness of the new finding. What often helps to obtain a grant is positively framing the perspective of a treatment target. Writing that you want to elucidate the pathophysiology first and decide on clinical usefulness later is more honest but unfortunately also a one-way ticket to the exit.

I am certain, though, that Dr van der Helm-van Mil and I are both of the opinion that thorough pathophysiological research is of tremendous value for the development of the field, and that scientists should do whatever they can to avoid that inappropriate framing of promising but immature scientific concepts lead to unintentional collateral damage in the clinic. Overdiagnosis and overtreatment are attributes of such damage.

\section{Robert B M Landewé}

Rheumatology \& Clinical Immunology, Amsterdam Rheumatology Center, Meibergdreef 9, Amsterdam, The Netherlands

Correspondence to Professor Robert B M Landewé, Department of Rheumatology, Leiden University Medical Center and Erasmus Medical Center, Amsterdam 2311, The Netherlands; landewe@rlandewe.n

Handling editor Josef S Smolen

Competing interests None declared.

Patient consent Not required. 
Provenance and peer review Commissioned; internally peer reviewed.

(c) Author(s) (or their employer(s)) 2019. No commercial re-use. See rights and permissions. Published by BMJ.

\section{A) Check for updates}

To cite Landewé RBM. Ann Rheum Dis 2019;78:e108.

Received 26 July 2018

Accepted 26 July 2018

Published Online First 10 August 2018

\section{G Linked}

http://dx.doi.org/10.1136/annrheumdis-2018-214156
Ann Rheum Dis 2019;78:e108. doi:10.1136/annrheumdis-2018-214172

\section{REFERENCES}

1 Van der Helm-van Mil A. Early identification of rheumatoid arthritis; the risk of overtreatment in perspective. Ann Rheum Dis 2019;78:e107.

2 Landewé RBM. Overdiagnosis and overtreatment in rheumatology: a little caution is in order. Ann Rheum Dis 2018:77:1394-6.

3 Turina MC, de Winter JJ, Paramarta JE, et al. Clinical and imaging signs of spondyloarthritis in first-degree relatives of HLA-B27-positive ankylosing spondylitis patients: the Pre-Spondyloarthritis (Pre-SpA) Cohort Study. Arthritis Rheumatol 2016;68:2444-55

4 Cutolo M, Sulli A, Smith V. Assessing microvascular changes in systemic sclerosis diagnosis and management. Nat Rev Rheumatol 2010;6:578-87.

5 EULAR. The EULAR campaign 2017/2018. 2017 https://www.eular.org/what_we_do_ dont_delay_connect_today_2017.cfm 